lateral pressure on the bronchial wall, to slip one blade of the forceps outside it and extract it. The localisation was not quite so easy, as the tube closely fitted the bronchus in which it had come to rest, caused no obstruction to the airway, and liad its thin upper end obscured by slight overhanging of the bronchial mucosa. The hairpin (Fig. 3) was a more difficult matter, as both ends sticking upwards were impacted at different levels in the bronchial wall, which was acutely inflamed and obscured by mucopurulent secretion. The distance of the object, and the small size of the tube that could be employed prevented both ends from being seen at the same time, and the obliquity was such that traction on one end would only result in the other end becoming more Firmly impacted. As attempts to approximate the ends by slipping a snare over them were unavailing it was decided to open the trachea low down. It was thought that lower bronchoscopy would afford greater power of mobility of the trachea, and there would be no possibility of the larynx being injured, as might easily have been the case, even if extraction by the upper method had been succesaful. A tube was inserted through the tracheotomy wound, one end of the hairpin grasped and pushed forcibly downwards, so that both ends might become disimpacted. By using a tube with an end cut very obliquely it was possible by the aid of forc'ps to get the sharp edge between one end of the hairpin and the bronchial wall. The tube was then pushed down and rotated until the other end of the hairpin was opposite the obliquely cut side of the tube. It was then seized with forceps and drawn into the tube, considerable lateral pressure being exerted on the bronchial wall. The obliquely cut tube made the procedure easier than would have otherwise been the case. Paterson was the first to see the advantage of an inner tube with the end cut obliquely, and his reversal of the usual Brüning's tube which has the outer one oblique and the inner straight ended is in many cases certainly an advantage.

The other bronchial case was quite straightforward, as the rounded-glass end of the shawl-pin was in the lower lobe bronchus and the point sticking upwards (Fig. 4), so that there was no objection to upper bronchoscopy, and the pin was drawn through the tube.

The laryngeal case was rendered more troublesome by the size and jaggedness of the object, the firmness of Jimpaction, and the delicacy of the laryox in a child of 9 months. A small tube spatula was used and just before the moment of extraction this was rotated laterally and its end pushed between the cords without loosening the hold of the forceps on the foreign body; in this way the cords were momentarily held apart whilst the object was disimpacted and guided between them without any injury occurring. It might have been expected that trouble would be caused by subsequent subglottic œdema, but fortunately this was not the case.

Harley-street, W.

\section{ACUTE EPIDIDYMO-ORCHITIS DUE TO BACILLUS COLI.}

BY W. P. BONNER, M.R.C.S. ENG., L.R.C.P. LOND.

THE patient, a man aged 45 , was admitted into the London Hospital on April 24th last, under the care of Mr. Hugh Lett. Twenty days previously he "strained" himself while lifting a heavy box at work. This caused him pain in the lower abdomen which was so severe that it made him sweat. The pain ceased after a few minutes, and after passing a large amount of urine he continued with his work as usual. Four days later he complained of frequency in micturition, at first every half hour, then seven to eight times a day and two to three times during the night. He consulted his medical man about this ; "the doctor gave him medicine" (no injection). Two days later he had pain in the right testicle, which came on during the night. The right side of the scrotum gradually became swollen and red. He never had any urethral discharge or pain on micturition. There was no previous history of any venereal disease; he married at the age of 20 , has had a family of 13 children, and his wife is living and in excellent health. No history of coitus since 10 days previous to the onset of the freqnency in micturition. No family history of any tuberculous disease.
On examination (April 24th) the patient was a poorly developed, ill-nourished man. Temperature $100.4^{\circ} \mathrm{F}$., pulse 94. The urine was acid, of specific gravity 1020, and contained a considerable amount of pus and mucus. The right half of the scrotum was swollen, red, very tender, and hot; the skin was adherent at the lower and posterior part. The right epididymis was extremely tender and enlarged so much that it almost covered the right testicle. The right testicle was swollen and tender (no hydrocele). The right spermatic cord was swollen and tender throughout the whole extent, which might be felt below the external abdominal ring. The right inguinal canal was tender on palpation. The urethra had a healthy appearance and was just moistened with clear mucus. No purulent fluid could be expressed by squeezing the penis. The prostate and vesiculæ seminales (felt per rectum) were not enlarged or tender. The left side of the scrotum and its contents showed nothing remarkable.

On April 30th the anterior portion of the urethra was washed out thoroughly with boric lotion. A sterilised soft indiarubber catheter of large size was passed without any difficulty, and a specimen of acid urine was drawn off. This specimen on microscopic examination showed a few pus cells and a quantity of coliform bacilli. Pure cultures of coliform bacilli were subsequently grown from this same specimen and an autogenous vaccine was prepared. On May 13th a soft fluctuating swelling appeared at the lower and posterior part of the right side of the scrotum. The skin over this area having been carefully prepared, the swelling was aspirated and a small amount of cloudy fluid obtained. Pure cultures of the coliform bacilli grew from this fluid. On May 15th the swelling (now more marked) at the lower end of the right scrotum was incised under a general anæsthetic. A small amount of material was removed which appeared to be almost entirely composed of disorganised tubules. No actual fluid pus was seen. On microscopic examination this material was found to be composed of a mass of necrosed tubules of testis and epididymis, coliform bacilli, and a few pus cells. Subsequently pure cultures of coliform bacilli were grown from this material. The urethra examined by the urethroscope appeared to be quite healthy; there was no stricture and no evidence of old or recent gonorrhœal trouble. Prostatic fluid obtained by massage of the prostate showed a few pus and epithelial cells, coliform bacilli, and staphylococci (no gonococci). Cultures taken from this fluid produced colonies of the coliform bacilli and staphylococcus albus. The coliform bacilli obtained on each of these four separate occasions were identical in structure and gave the reactions of Friedländer on sugars. Carefully taken radiographs showed no sign of any pathological conditions in the regions of the kidneys, ureters, or bladder.

The treatment of this case was as follows:-Rest in bed with the scrotum well suspended. Locally, at first, the application of moist heat in the form of boric fomentations and later (after incision) daily dry dressing with plain sterilised gauze. Medicinal: Maintaining the reaction of the urine alkaline by the administration of citrates and bicarbonates; bladder sedatives, hyoscyamus and buchu. Vaccine: Gradually increasing doses of the autogenous bacillus coli vaccine were given once a week, commencing with 5 millions and increasing up to 100 millions.

The patient has made an excellent recovery, the affected area of the right testis and epididymis being now represented by a small fibrotic nodule. The left epididymis and testis remain unaffected.

This case seems to suggest that some of the conditions of acute epididymo-orchitis of obscure origin, frequently associated with a history of strain, are due to an infection with the bacillus coli, brought on by a strain while the bladder is full of urine. I am indebted to $\mathrm{Mr}$. Lett for permission to publish the case and for urethroscopic examination to Mr. F. S. Kidd for investigating the prostatic fluid and also examining the urethra; and to Mr. T. H. O. Benians for the preparation of the autogenous vaccine and the bacteriological investigations.

A German Female Medical Officer of ScHools. - The municipal authority of Berlin has appointed Fräulein Martha Ulrich, M.D., as school medical officer, she being the first medical woman to obtain one of these school appointments. 